\title{
From the Perspective of the Times to Research the Application of Ergonomics in the Tractor Moulding
}

\author{
Wei Chen \\ Jiangsu Open University, Nanjing, China
}

\begin{abstract}
The application of ergonomics in the tractor modeling has experinced three phases. They are design phases of mechanical center, "man-machine" system and "man-machine-environment" system. In the design phases of mechanical center, only considered mechanical design in terms of mechanics; In the design phases of "man-machine" system, man's factor was attached importance to, relation of man and machine was emphasized. In the design phases of "man-machine-environment" system, man's importance in the system and harmony of man-machine-environment were stressed. Each phase of change reflects the development of science and techonology, the progress of human design ideas, and the change of human values.
\end{abstract}

\section{Keywords-times; ergonomics; tractor moulding; design phase}

\section{INTRODUCTION}

Ergonomics is a marginal subject, which has developed rapidly since the 50's of last century. From people's physiological and psychological characteristics, the relationship among human man and environment is researched in improving the overall effectiveness of the human-man-environment system.

In the tractor modeling desing, the use of ergonomics is to make desinged tractor not only have novel style and the sense of times, but also meet the requirements of various functions of the human body. That is, in apperance can provide the feeling of beauty including visual and tactile to operators; in the modeling can make the operation easy, light, comfortable, safe, reduce their manual labor and mental burden. Specifically, in the tractor modeling desing, the most closely related to ergonomics is its cab, seat, indicating device, control device etc.

The application of ergonomics in the tractor modeling has experinced three phases [1], which are design phases of mechanical center, "man-machine" system and “man-machine-environment” system.

Each phase of change reflects the development of science and technology, the progress of human design ideas, and the change of human values.

\section{DESIGN PHASES OF MECHANICAL CENTER}

Before the invention of the tractor, power used for agriculture was livestock power involving cattle, horses etc. and manpower. This period belonged to the period of manual labor, human being were in a slavery and affiliate position.. The invention of the first steam tractor ended the history in which human being always used livestock power and manpower as power. To it as a symbol, the agricultural production entered the mechanical age. Early tractors generally did not have a cap, the drivers would suffer from the the sun, wind, rain and dust, and they were not safe. The seat was replaced with iron toolbox. Its modeling had not consider factors about the man's structure, scale and motion etc. So the drivers sitting in the seat not only easy to produce physical fatigure because of strong vibration, but also when they saw a cold seat, they would produce disgust feeling in their psychology, to influence their mental state, ultimately would speed up their mental fatigure. Figure 1[2] is early tractor modeling. In the figure, you can see that the arrangement of all kinds of control rod is messy, the lack of formal beauty. Also can see that this design did not conform to man's psychological and physiological characteritics. Because there were no suitable handle shape in all kinds of control rod, the driver's hand was not very uncomfortable. Because pressure gauge on the steam engine is far away from the driver, and the more middle blocks, it was not seen clearly, to lead to their visual fatigue, identifying error, eventually lead to their attention not focused ,or would accidents was occured.

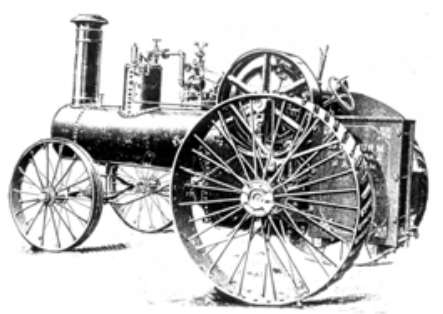

FIGURE I. THE EARLY TRACTOR MODELING

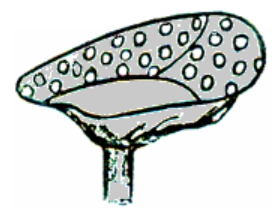

\section{FIGURE II. THE MODELING OF EARLY TRACTOR SEAT}

Along with the development of tractor industry, during end of 19 century to early of 20 century appeared a tractor with an internal combustion engine as a driving power, so that the mechanical performance of the tractor had been greatly improved.The design of the seat begingged to pay attention to the shape, as shown Fig.2[2]. Each side of the seat imitated man's hip to be designed the shaoe of the bucket. The driver sit in the seat to feel more submissive. Some holes were opened 
on the seat, which is conducive to ventilation. The seat was better than the previous "seat", but due to the material is made of iron, the driver feeled very cold in the winter and did very hot in the summer. Psychologically, they were afraid to sit in this seat The connection of seat and body is rigid, their vibration is very powerful, the driver was easy fatigue In addition, due to the function of the tractor was not too much, the instrument and operating parts were not much; Most of the instrument were the shape of a circular pointer type which was little change in size and shape. For a long time, the driver feeled monotonous and dull. The operating parts mainly are the device of controlling throttle, the device of controlling clutch, and the shift device a well as steering wheel. These devices were made of no decorative iron, there is no feeling of kind and pleasant. All of these parts were not designed according to the human factor.

At that time, there was no cab on the tractor. The noise near the driver's ears is very high, easy to make his physical strength produce fatigue.

To the last centure 30's, with the developoment of science and technology, some new technologies, new materials etc. were used to tractor. The application of hydraulic technology reduced the labor intensity of the operator. The continous improvement of engine, and the use of rubber tires mitigated the vibration and noise of tractor. The cab was installed in a small number of tractors, which reduced the number of casualties. During this period, although human factor was considered, this was only parts. The shape of the instrument and operating parts and their alignment position were the same as before, and not much improvement.

Throughout this phases, with the progress of science and technology, the mechanical performance of the tractor was gradually improved, but considering the human factor was not much. So the operators wanted to adapt to a variety of mechanical devices, vibration and noise, also adapt to a variety of climate change, might encounter rollover risk.

During this phase, the designers mainly considered the design of the mechanical aspects on the tractor's performance, mechanism, and so on, so this phase was the design phases of mechanical center

\section{DESIGN PHASES OF "MAN-MACHINE" SYSTEM}

In the 50's, the mankind was in the relative peace time, the human being as an importment factor got attention. Ergonomics as a discipline has been formally established. Some developed countries began to study "man-machine" system. Tractor modeling also began to really consider the human factor. In addition to further improve the various mechanical performance of the tractor, the modeling desige of the cab, the seat, the operating parts and instrument etc. were widely researched.

\section{A. The Modeling Desige of the Cab}

One of the main research object of ergonomics is the safety of people. Making the operators get the maximum safety protection device is the cab.

The tractor can work in the field, transport on the road. In addition to the shock, the operators were still subject to the influence of cold and warm, rain and snow, wind and sand, which severely affect their normal work. The tractor was easy to rollover to cause accident. It was necessary to install the cab from the perspective of human machine engineering. At first, the tractor 's cab was a simple pavilion shape ceiling made of canvas or sheet metal, which was supported by four pillars.This cab is simple in structure and low in cost. To a certain extent, it can prevent the sun and the rain, but it can not prevent dust, also did't heat preservation. And its moulding is not beautiful, lacks unity. By the 60s, the tractor generally used the enclosed assembly cab, which both reduced the casualties and made its moulding beautiful.

\section{B. The Modeling Desige of the Seat}

For the previous seat features of large vibration and small space, in the 50s, the seat moulding was improved, as shown in figure 3[3]. The spiral springs and the curved cantilever on the seat can absorb shock. The seat space was increased to make the person's hip have larger space. Greatly reduce the driver's mental fatigue and physical fatigue.However, the hard seat made the driver sit up to feel uncomfortable, psychological nervous, and the legs were subject to the constraints of seat periphery. In the 60s, the seat moulding was improved again, as shown in figure 4[3]. According to the human body structure and the comfortable degree when they were driving, the size of the seat (include the height of the seat, the depth of the seat, the width of the seat and inclination of the seat back and so on ) was designed. The cushion of the seat is made up of soft stuffing and leather. The drivers sitting in this seat feel very confortable, their the back, hip and legs were not easy to fatigue, they feel at ease in their psychology.

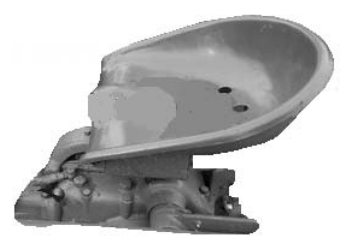

FIGURE III. THE MODELING OF 50S TRACTOR SEAT

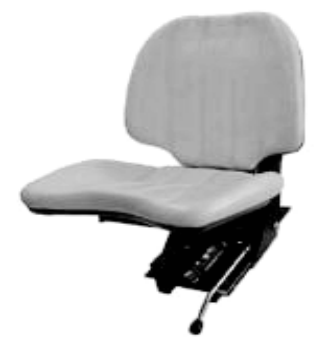

FIGURE IV. THE MODELING OF 60S TRACTOR.SEAT

\section{The Modeling Desige of the Operating parts and Instrument}

During this period, the moulding of the instrument and the operating parts was begun to focus on. The instrument of the popular round pointer types was transplanted to the tractor, and it was placed in the human visual center, to reduce human visual fatigue. The body design of the operating parts was as 
reasonable as possible, which conformed to the human physiological characteristics. The national standards on the geometrical dimension of the handle were established by some countries. The handle was made up of plastic or rubber, which could not only beautify the operating parts, but also avoid the direct contact with the metal.

Throughout this phases, with the rise of ergonomics, the moduling design of the tractor started to pay attention to the human factor. When the new material and new technology were applied to the moduling design of the tractor, it provided the aesthetic factors including the visual and tactile etc. in the appearance, and did the convenient operation in the moduling , to make the drivers not appear mental fatigue and physical fatigue at work. So this phase was the design phases of "man-machine"system

\section{DESIGN PHASES OF “MAN-MACHINE-ENVIRONMENT” SYSTEM}

Into the $70 \mathrm{~s}$, due to the application of vrious new technology, vrious automatic devices and computer, which promoted the rapid development of the tractor industry. At the same time, in the field of science, because the emergence of systems engineering, cybernetics, theory of information and other disciplines, "man-machine -environment"system was established in the man machine engineering, to fundamentally begin to change enslaved status by which human was machine before. With social stability, material richness, the purpose that all design is to serve the human being was put forward .The environment is the condition of human existence, so the more developed society, the more developed industry, the people shoule more emphasize the environmental awareness.

Broadly speaking, the environment includes all factors related to human activities. For the tractor moulding, the environment mainly comprises the shock absorption and moulding of the seat, the moulding and arrangement of the instrument, the moulding and arrangement of the operating parts, the noise contral and climate regulation of the cab interior, the safety and the visual field of the cab. During the design phases of "man-machine"system, people had some research on the environment, but not as a system to study. And now, especially today, for the tractor moulding, the environment must be as a system's factor to consider, in order to effectively play the role of people, and to provid a safe and comfortable environment for the operators, which improve their work efficiency.

\section{A. The Shock Absorption and Moulding of the Seat}

In the seat moulding, in order to further reduce the vibration, the moulding was designed as shown in figure 5[3]. It is made of four bar mechanism, the helical spring with pre-tightening force of stepless adjustment and constant rigidity, shock absorber with reducing power etc. The structure of the seat is more capable of reducing vibration. The back of the seat was designed to be a bending shape, which was suitable for the human lumbar spine. The whole seat could adjust the leve and tilt in order to adapt to the sitting posture of different operators.

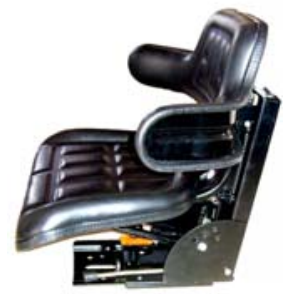

FIGURE V. THE MODELING OF TODAY TRACTOR.SEAT

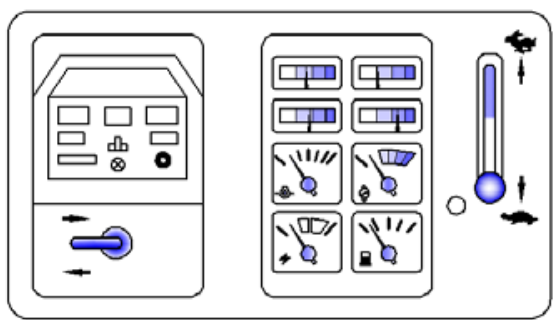

FIGURE VI. THE MOULDING AND ARRANGEMENT OF 90S TRACTOR INSTRUMENT

\section{B. The Moulding and Arrangement of the Instrument}

In this period, the moulding and arrangement of the instrument occupied a very importment position in the moulding design of the driving cab. That human's visual fatigue can make his mental stress easy to generate operational errors. In order to prevent visual fatigue, the movement of the eyes should be cut in the human's working process, so fitting to human visual features was focused in the moulding and arrangement of the instrument. In the 1940s and 1950s, because the shape of the instrument was affected by streamline, in general, its shape was round. Time long, this shape appeared very clumsy, so In the 1980s and 1990s, simple rectangular shape came into being. Figure 6[4] is moulding and arrangement of 1990s the instrument. The instrument panel is rectangular, in order to obtain the shape of the uniform, the various display devices on the instrument are also rectangular. In the overall shape of the rectangular, the switch of the signal lamp is the round, which there is a change in unity. In order to improve the speed and accuracy of interpretation, in a rectangular shape, there is a arc graduated scale. And the various display devices on the instrument were focused on the effective human visual range, to make human eye movement as much as possible to reduce. The research shows that arc graduated scale is better on the speed and accuracy of interpretation, therefore, at present, althought the shape of the instrument panel is still a rectangle with an arc, the moulding of various instruments is round, as shown in Figure 7[5].

\section{The Moulding and Arrangement of the Operating parts}

The modelling of operating parts include their geometry size, their arrangement location and the shape of the handle. Their geometry size is associated with the control system design of the whole machine, which can be obtained through checking the relevant manual. The arrangement position of the operating parts should comply with the human physiological characteristics. Generally, the main gear lever, deputy gear lever, control lever of hydraulic system are respectively on the left front, right front and the left operating counters of the seat. 
Such, the driver's operation is often not use his eyes to find the required operating parts, neither error nor visual fatigue. The clutch is on the left side, the brake and accelerator are on the right according to the order from left to right. Generally, the appearance of operating handles is designed according to the size of the hands, the palm muscles and the handle contact position. Figure 8[6] is some of the common control handle shape. The steering wheel uses hydraulic steering system, its height and inclined angle can be adjusted freely according to the needs of the driver's driver, thus they can conveniently operate.

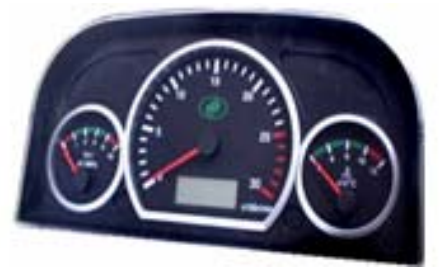

FIGURE VII. MOULDING AND ARRANGEMENT

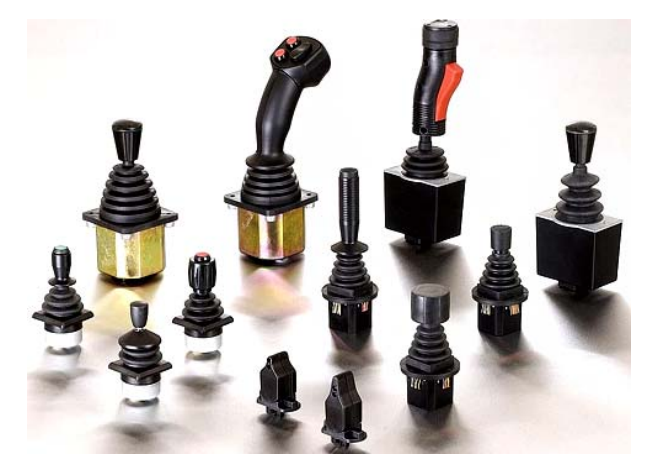

FIGURE VIII. MOULDING OF COMMOND OPERATING PARTS OF TODAY TRACTOR INSTRUMENT

\section{The Noise Contral and Climate Regulation of the Cab Interior}

With the development of new technology and new material, the fully enclosed cab appeared in the 20 century 70s. The sound-absorbing material and vibration absorbing material were installed in this cab. The joint of floor, wooden partition, door and window inlayed rubber sealing strip, greatly to reduce the noise near the driver's ear. In addition, fully enclosed cab is conducive to heat insulation, vibration absorbing damping, windproof, dustproof, thus to improve the driver's working environment.

For exchanging fresh air, the air conditioning or ventilation device is installed on the roof, to make the driver no stuffy feeling. The cab also has a cigarette lighter, ashtrays, CD player, which become a pleasant living room rather than a cold iron box. The cab indoor colour is partial cool color with low lightness generally, to make the drivers produce a gentle and quiet feeling in the vision and psychology, to them work with happy mood and full spirit

\section{E. The Safety and the Visual Field of the Cab}

With the further research of ergonomics, the problem of security is primacy. According to the statistics of Europe and the United States, the deaths in agriculture were for about $40 \%$ $\sim 60 \%$ caused by tractor overturned

Since the $1970 \mathrm{~s}$, many countries have vigorously carried out the research about tractor's dynamic overturn mechanics and characteristics, so that the dynamic stability of the tractor has fundamentally improved by the overall design of the tractor and the reasonable selection of the whole machine parameters.

The arrangement of cab seat was on the location of the great vision. Using a large area glass door and window as well as the mirrors guaranteed the driver looking around in all directions, to monitor working condition. Figure 9[7] is the modern tractor moulding

Throughout this period, with the deepening research of the man-machine engineering, the human paied more attention to their own safety, paied more attention to their own comfort, more emphasized on their own psychological meet in their work, more concerned about the impact of environment on their own, So this phase was the design phases of "man-machine- environment"system.

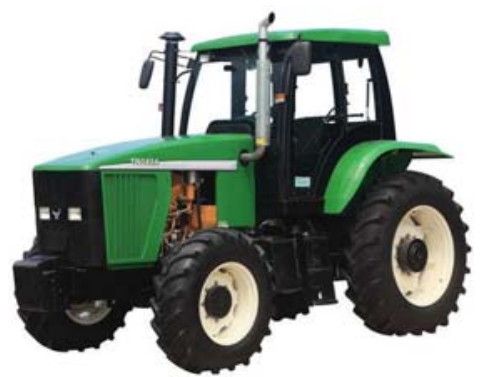

FIGURE IX. THE MODERN TRACTOR (INSTALLED THE CAB) MOULDING

\section{CONCLUSION}

To sum up, by analysing three stages of the application of ergonomics in tractor modelling, you can see that before the invention of the tractor, the human gained working achievement by their great fatigue; In design phases of mechanical center, the human only considered mechanical design, so the machine could not adapt to their operating requirements; In design phases of "man-machine" system, the moduling design of the tractor started to pay attention to the human factor, and the research of man-machine system was extensively carried out; In design phases of "man-machine-environment" system, the people as the first factor were considered, particularly emphasizes the people basic value, emphasizes the importance of people in the system design, emphasizes the necessity of the coordination in human - machine - environment

\section{ACKNOWLEDGMENTS}

This research was supported by project on science and technology innovation team about application of the internet of things technology.

\section{REFERENCES}

[1] Wei Chen, Zhenbang Chen. A Sense of The Times About Tractor's Moulding. Journal of agricultural machinery, 1995, 26 (3) : 119-123 
[2] Wei Chen. The evolution factors on the tractor moulding. Journal of Jiangsu university of science and technology, 1994, 15 (6) : 30-35

[3] Anonymity: The tractor seat pictures[EB/OL]. http://image. haosou.com/i? q= The tractor seat pictures \&src=srp

[4] Zhenbang Chen. Agricultural machinery moulding aesthetic. Mechanical industry publishing house, 1986

[5] Anonymity: The picture on high-definition tractor dashboard[EB/OL]

http:// image.haosou.com/i?q= The picture on high-definition tractor dashboard \&src=srp, Anonymity: The tractor control handle pictures[EB/OL]. http://image.haosou.com/i?q= The tractor control handle pictures \&src=srp

[6] Anonymity: The tractor picture books[EB/OL]. http://image. baidu.

com/search/ detail? $\mathrm{z}=0 \&$ ipn $=\mathrm{d} \&$ word $=$ The tractor picture books\&step_word 